UNIVERSITY OF CHITRAL JOURNAL OF LINGUISTICS AND LITERATURE

VOL. 5 | ISSUE I | JAN - JUNE | 2021

ISSN (E): 2663-1512, ISSN (P): 2617-3611

\title{
Constitutive Features of Deliberate Language Shift: A Case Study of Afghan Immigrants as a Community of Practice
}

\author{
Dr. Zulfiqar Ali \\ Associate Professor, Department of English \\ City University of Science and Information Technology, Pakistan \\ zulfiqar.ali775@yahoo.com \\ Sohail Hussain Sheikh \\ sohailsheikh77.ss@gmail.com \\ Dr. Tariq Khan (Corresponding Author) \\ Assistant Professor, Department of English \\ University of Malakand, Pakistan \\ tariqkhan1975@gmail.com
}

M.S. Scholar, City University of Science and Information Technology, Pakistan

\begin{abstract}
The study is aimed to determine the constitutive features of deliberate language shift by Afghan immigrants in Chakwal (Punjab, Pakistan). The researchers selected 10 business practitioners living for at least 10 years in the Punjabi community. The semi-structured interviews and nonparticipants observations were conducted for data collection. The researchers used "Community of Practice" (CofP) as a theoretical framework. CofP Model has three elements that helped the researchers determine the constitutive features of language shift by Afghan immigrants. The researchers found out that the regional displacement left the Afghan immigrants with the least liberty to exercise their language in all the fields of life because the local stakeholders were not conversant with Afghan's language. As a result, they started borrowing words from Punjabi and Urdu languages. The study's findings reflect that the influence of these languages permanently substituted their native language vocabulary with that of Panjabi and Urdu. The researchers noticed that linguistic adaptations are tactically intentional and need-based and not accidental. The market competition is the driving force towards their deliberate language shift. This language shift is determined through practitioners' attitudes and communication attempts to generate more significant revenue and make better fits in the community of practice.
\end{abstract}

Keywords: Language shift, Afghan immigrants, Community of practice. 
UNIVERSITY OF CHITRAL JOURNAL OF LINGUISTICS AND LITERATURE

VOL. 5 | ISSUE I | JAN - JUNE | 2021

\section{Introduction}

\subsection{Background of the Study}

Moore (2011) coded that Pakistan is located in South Asia, neighbouring India, Iran, China, and Afghanistan. Among these states, Afghanistan has been the area of military conflicts even after the withdrawal of European masters from the regions (Mackey, 2006). The region has witnessed multiple military wars - internally and externally. Euro-America has attempted to take control of this region but failed on account of numerous geostrategic reasons. Because of these military conflicts, the most affected areas are Afghanistan and Pakistan, as they share a long border strip (Zaidi, 2010). These wars affected the commoner's life in the region, and ultimately, they saved their lives by flooding away their localities.

With the outbreak of the Afghan Taliban war with the U.S military forces, the number of Afghan Pashtun immigrants have been increased all around Pakistan. Predominantly, they moved to Punjab and settled in different cities for the security and livelihood of their families (Khan, 2005). They brought their workforce and sought the labour in the Punjab region-the agrarian land, having forests along with five opulent rivers. These were the homeless people, and the inhabitants of the localities welcomed them out of their religious affiliations (Mackey, 2006). The first generation of immigrants tried to sustain their Afghan culture, but the next generation adapted the host culture, including the Punjabi language. The significant changes appeared in the following domain of their lives:
a. Fashion and Random Fluctuation;
b. Language (mainly transactional language); and,
c. Social Needs.

\subsection{Afghan Immigrants as a Peripheral Membership}

Since the Afghan immigrants settled in Punjab, they established their businesses and social connections with the regional and local parties. At the outset, they earned the sympathies of local inhabitants and sought labour for livelihood. However, besides all these practices, they could not harmonise with the local culture. They did not find a common domain where they could share their mutual interests. They remained distinct from the locals and kept practising their indigenous culture, which did not earn any reputation, monetary benefits, or social 
UNIVERSITY OF CHITRAL JOURNAL OF LINGUISTICS AND LITERATURE

VOL. 5 | ISSUE I | JAN - JUNE | 2021

recognition. They remained peripheral in the Punjabi community. Nonetheless, an early realisation brought many changes to their lifestyle, and an era of deliberate language shift got its origin.

\subsection{Problem Statement}

Afghan immigrants and Punjabi culture are in contrast ranging from their food and language to rituals. They share no similarities except their religious faith. Their tongues are utterly incomprehensible to each other. Owing to their cultural differences, they do not concede with cultural fusion-and-even to exogamy. Their dress codes are different from one another, with a lot more differences in their celebrations of the same religious occasions. Even after immigration from Afghanistan, they still own a great affiliation with their cultural customs and geographical rituals. However, their prolonged stay in Punjab needed adaptability to multiple changes, especially in food, clothes, cross-cultural marriages, and language, to survive and fulfil their transactional purposes. Since language is the key component to accomplish transactional goals, the Afghan immigrants' speech has been significantly adapted. It has been observed that they just not only learned Urdu and Punjabi for business transactions; instead, they borrowed native terms and replaced their Pushto words to make their language moderate and flexible.

\subsection{Research Question}

- How CofP led to the constitutive features of deliberate language shift among Afghan immigrants in Punjab, Pakistan?

\subsection{Research Objective}

- To determine the constitutive features of deliberate language shift among Afghan immigrants in Punjab, Pakistan.

\subsection{Rationale and Significance of the Study}

The study aims to determine the sociolinguistics features which affect the lives of Afghan immigrants. The apparent changes and everyday observations regarding the immigrants' lives enhanced the significance of the subject of the study. The study accentuates the reversal of Pashtun culture as well as of language. There are plenty of significant changes, which ought to be investigated to highlight the sociological factors affecting the lives of Pashtun immigrants in district Chakwal (Punjab). 
UNIVERSITY OF CHITRAL JOURNAL OF LINGUISTICS AND LITERATURE

VOL. 5 | ISSUE I | JAN - JUNE | 2021

ISSN (E): 2663-1512, ISSN (P): 2617-3611

\section{Literature Review}

Afghanistan is a landlocked country that shares one of the most friendly borders with Pakistan (Raza, 1991). For many decades, there was no check and balance on the movement of the immigrants at this very border. However, Pakistan always declared its border with Afghanistan the safest one as both the countries had unwavering confidence in each other (Mackey, 2006). Because of this, several transactional trips were made relatively quickly along with the free movement of local masses as on both sides; people used to speak the same language (Saleem, 2008). Moreover, along the border, people share the same social customs, cultural norms, and worldview.

With the outbreak of two consecutive wars with the USSR and the USA, the war victims were immediately displaced from the threats and moved to Pakistan and settled in different cities (Zaidi, 2010). The most accessible and welcoming cities were in Khyber Pakhtunkhwa and Punjab, including Attock, Chakwal, and Khushab. After settling the disputes, most immigrants preferred to stay in Pakistan because of the socioeconomic opportunities. Moreover, they did not pay any considerable taxes to the government of Pakistan (Chitkara, 1996). They enjoyed the soil of Pakistan as the fostering mother with no external check and balance (Ahmad, 1998). According to the latest government survey and the record of NADRA, around three million displaced Afghans reside in Pakistan, which is a vast number to dent the economy of Pakistan.

\subsection{Sociocultural Conflict Between Afghan Immigrants and Punjabi Communities}

According to Khan (2005), there is no one-to-one correspondence between Afghan and Punjabi cultures. The diversification is found in their dress code, language code and even behaviour code. Superficially, they share nothing similar except religious faith. With the arrival of Afghan immigrants in Punjab, the local inhabitants had a unique experience of an exotic culture, which did not attract them immediately (Zaidi, 2010). As the minority in the region, Afghan immigrants sought refuge to acquire the local culture to maintain amicable contact with the localities. They had opted for it to establish their business and secure social stability in the market (Ahmad, 2001). 
UNIVERSITY OF CHITRAL JOURNAL OF LINGUISTICS AND LITERATURE

VOL. 5 | ISSUE I | JAN - JUNE | 2021

ISSN (E): 2663-1512, ISSN (P): 2617-3611

\subsection{Language Dominates the Culture in Pakistan}

English was declared as the official national language in the constitution of 1973. The legacy of English colonisers remained official even after they departed from the region (Shah, 1997). However, English retained the language of power corridors and was used at higher level education as a medium of instruction and among all the country's powerful institutions. It has even influenced our national languages, like Urdu, Punjabi, Pashtu, Sindhi, and Balochi (Rehman, 2003).

In a country like Pakistan, the children lay open to multiple languages, which are entirely different at the macro and micro levels, linguistically. They set out to experience it from the outset of their language and culture acquisition process. They raise in a linguistically diverse and dynamic environment (Saleem, 2008); they are generally nurtured in homes where their parents speak their mother tongue (Rauf, 1975).

To Saleem (2008), children perceive the fundamental concepts about the objects around them in their mother tongue, and the culture they perceive becomes the product of that set pattern of language. Their exposure to markets, schools, and playgrounds inculcate the cultural aspects intermingled with their language, and they communicate and transmit the cultural norms with their peers by adopting the fixed culture. However, such exposure helps them enhance their linguistic skills and add a new language to their linguistic competencies. Hence, a language becomes the product of culture, and culture can only be transmitted and preserved in the language of everyday practice (Baarat \& Sindhi, 2003).

\subsection{Hybridisation as a Conversational Strategy}

The scope and significance of language in everyday business can never go unnoticed. Language has both functions: conversational and transactional. However, it entails a complex and scientific process. People use language for several functions without conscious effort as they take the language for granted as a means of expression. Hudson (1980) pointed out that people acquire language from a society where they are brought up without a deliberate struggle. Furthermore, language is a social phenomenon. According to Lyon (1981), language and culture are deeply interceded, as both can interpret each other. 
UNIVERSITY OF CHITRAL JOURNAL OF LINGUISTICS AND LITERATURE

VOL. 5 | ISSUE I | JAN - JUNE | 2021

ISSN (E): 2663-1512, ISSN (P): 2617-3611

Hybridisation is usually done for some transactional strategy. In this strategy, the interlocutors shift their medium of instruction and expression. Gumperz (1982) called it the juxtaposition of different internal structures within the same language. Besides, it is classified into two categories: situational code-switching and metaphorical code-switching. In situational code-switching, the variation in language use is dependent on the situation rather than the topic. Whereas, metaphorically, code-switching is conditional to the change in topic amongst the interlocutors. Scholars have further subdivided categories of code-switching as: tag switching, intra-sentential, and inter-sentential.

It refers to the regular transferring of semantic elements between the two languages, sometimes more than two languages depending on the literary background of interlocutors. Terence (1989) extrapolated that code-mixing is the variation and shifting between one or more than one characteristic of two or more languages. Though, compared to code-switching, codemixing needs more delicacy and care because, in code-mixing, the interlocutors have to be cautious in adjusting the codes in different scenarios that should match the target language context. It is tricky and demands mastery because the speaker must be vigilant about subjectverb agreement, gender, and the number. Depending on the language community, the frequency of code-mixing is quite hindered. It may vary from language to language. The claim may be witnessed in Pakistani linguistic communities. In the Punjabi context, code-mixing has a higher frequency of code-mixing. Contrastingly, the Pushto language community has a comparatively low relationship between language and culture in Punjab.

To acquire the language and culture is not the choice of the speakers; instead, to make a better fit in the society, one automatically receives the language and culture where one was raised. Individuals have no control over that acquisition, and this phenomenon becomes the practice of social beings. Sociocultural norms are so inculcated that one automatically behaves in culturally set patterns.

In Punjab, all the modern societies are heterogeneous, and such societies want to transmit and adapt the culture through dynamic exposure. Punjabi communities require mastery over more than two languages, at least even within a single culture. People have to speak a language 
UNIVERSITY OF CHITRAL JOURNAL OF LINGUISTICS AND LITERATURE

VOL. 5 | ISSUE I | JAN - JUNE | 2021

ISSN (E): 2663-1512, ISSN (P): 2617-3611

at home, entirely different from those expressed in streets, markets, schools, or workstations. Such practice and exposure make the Punjabi culture dynamic (Rahman, 2003).

The central role in acquiring the language and culture is performed by primary level education that allows the students to express their learning and conceptual understanding in their mother tongues. However, when they appear in competitive exams which require the same cognitive and critical thinking in the English language, they cannot succeed (Saleem, 2008).

\section{Research Methodology}

The researchers used a qualitative approach to collect the perceptions of the Afghan business community in district Chakwal as a source of data for analysis. The researchers analysed the data by transcribing the interviews. For triangulation, the non-participant observations are also collected.

\subsection{Wenger's CofP as a Theoretical Framework}

Since the sociolinguistic features and factors that affect the language of any community are a matter of individual's and collective experience, the researchers selected the "Community of Practice" as a theoretical framework. Wenger (2011) pinpointed that people do not learn from others' experiences; instead, they also incorporate their experiences in changing others' outlook on life. The framework has three constitutive elements on which the entire model stands. The "Domain" is the first underpinning principle of this model that deals with the area of interest for the population. It brings the practitioners closer to creating a unique identity to address the common issues and challenges. The second element is "the Community", which constitute a valuable relationship among the practitioners. It defines the quality of relationships among the members. It also examines and determines the internal and external boundaries. The "Practice", according to Wenger (2004), is the body of knowledge, experiences, and methods the members share within that community. The practice is a way of acting under certain circumstances. The behaviour of practitioners is altered according to the purpose and intentions for a set goal.

It led the researchers to apprehend the phenomenon's essence by investigating the participants' viewpoints who have been experiencing it for almost the last two decades. Qualitative research is necessitated to analyse the data collected through interviews. The researchers used the thematic content analysis technique to conclude the results of the study. 
UNIVERSITY OF CHITRAL JOURNAL OF LINGUISTICS AND LITERATURE

VOL. 5 | ISSUE I | JAN - JUNE | 2021

\subsection{Population}

All the Afghan Pashtun immigrant businessmen in district Chakwal is the population of the study. The population is selected regardless of their business property and market influence. All sorts of people in business got an equal opportunity to be a part of the study.

\subsection{Research Sample and Sampling Technique}

The motive of sampling is to limit the population to a small set of people from a speech community and oversimplify the inhabitants. This limitation provides a logic that it could deliver rationality, meticulousness, articulacy and acceptance. The researchers opted convenient sampling technique in limiting the population for the study. This technique generated a sample that epitomises the entire population unaffectedly.

\subsection{Data Collection Tools}

The researchers collected the data through observations and semi-structured interviews. They administered a total number of 10 individual interviews. Each participant had at least 10 years of stay experience in the locality. Their perceptions were recorded with their consent which the researchers for thematic analysis later on transcribed. Besides the recordings, the researchers also jotted non-participant observations to triangulate the same interviewees during their transactional dealings with the customers.

\section{Findings and Analysis}

The analysis of the interviews and observations revealed how Afghan immigrants established the community of practice in collaboration with the local inhabitants. The CofP model is used to systematise the themes derived from the research participants' interviews and observations. The themes are further discussed and interpreted under each element of the CofP model. Through the underpinnings of CofP model, the entire debate is constructed to open up the constitutive features that deliberate the language shift under certain circumstances.

\subsection{The "Domain" as an Element of CofP}

The domain is the fundamental zone of communal practices. It leads to the emergence of new social phenomenon. That is the precinct where practitioners share their experiences and knowledge. Two separate communities can fuse by establishing some everyday tools to interact. However, the common domain between Afghan and Punjabi communities was set through 
UNIVERSITY OF CHITRAL JOURNAL OF LINGUISTICS AND LITERATURE

VOL. 5 | ISSUE I | JAN - JUNE | 2021

ISSN (E): 2663-1512, ISSN (P): 2617-3611

business markets. To practice the domain, the Pushto speaking immigrants took support from sociolinguistic features.

The researchers observed that Afghan immigrants' code-switching between Pushto and Punjabi is purely a matter of choice as it provides ease to their customers in dealings. It mainly occurs when the customers are either of old age Punjabi or illiterate. Yet, it is difficult to maintain for a prolonged discussion period because Afghan immigrants have the least opportunities for such conversations. They coded that we are conversant in the Urdu language, but Punjabi is a bit hard accent with difficult pronunciation like Pushto, which makes it challenging to acquire fully. They also professed that a prolonged conversation creates a painful experience for their articulators. Their articulators are not set according to the Punjabi language utterances, the participants reported.

The second feature claimed by the research participants and observed by the researchers is code-mixing. The participants informed that they are used to uttering the local Punjabi words during the conversation with their Punjabi customers because it creates a unique effect as they perceive. They also reckon that their customers enjoy their broken and mixed Punjabi as they usually smile and some also laugh. They believe that it develops an environment of mutual understanding between sellers and buyers. Additionally, they are accustomed to practising in their daily conversations, even among their speech communities, as it has become their secondary habit.

\subsection{The "Community" as an Element of CofP}

The Sociolinguistic adaptations are tactically intentional, need-based, and not accidental, as reported by Afghan immigrants. They coded that they are doing their business in the market, full of competitors. These competitors are not from the other speech community but from among their language speakers as well. Thus, it is the need of time to make a better fit in the market. They reported that the first feature that attracts their customers is the ease of communication and their affectionate attitude even before the concessions and open access to the articles they are selling. They stressed the concept of communication and rapport to attract buyers and make better transactions compared to their competitors. 
UNIVERSITY OF CHITRAL JOURNAL OF LINGUISTICS AND LITERATURE

VOL. 5 | ISSUE I | JAN - JUNE | 2021

ISSN (E): 2663-1512, ISSN (P): 2617-3611

The immigrants reported that the second factor leading to the language shift is their target buyers, who belong to a completely different speech community. To make a successful transaction, they intentionally make this shift in their native language. One of the participants responded that business demands these shifts and should never offend anyone because it produces a good revenue for them at the end of the day. He also suggested that business and livelihood always have greater prestige than language and culture. Resultantly, no participant regretted this language shift as they made no efforts to maintain their own language. Instead, they put their best to become more proficient in Punjabi and Urdu language as the coded participants. They professed that they do not look down on Punjabi and Urdu languages because they also provide a medium to make better business deals.

Additionally, they stressed the concept of professionalism that demands to be supportive towards their customers. They reiterated that ensuring the open access of their business goods for the customers is a significant challenge. It is also reported that ease and access is the hallmark of each customer's satisfaction which produces a better revenue for the seller. Code mixing and code-switching are fundamental tactics for Afghan immigrants to improve the quality of access and ease. The participants stated that customer's satisfaction is directly proportional to their professionalism.

Lastly, the most significant transactional factor to the Pashtun language shifts business expansion by making one-to-one ties with the local culture. The participants stated that prolonging their stay in Pakistan depends on the versatility of their business, for which they are endeavouring hard. They indicated that they had been given multiple deadlines to leave Pakistan otherwise to deposit a considerable revenue to the local government to make their stay legitimate in Pakistan.

\subsection{The "Practice" as an Element of CofP}

The "domain" and the "community" are established to do effective practices in a speech community. The participants reflected upon is the interaction as a fundamental practice for their communal relation. Business aside, they admitted that they have been living here for the last 2 decades, enough to be engrossed in any new culture. They stated that their children were born here and were educated in the local schools. Their socialisation in that community has enabled 
UNIVERSITY OF CHITRAL JOURNAL OF LINGUISTICS AND LITERATURE

VOL. 5 | ISSUE I | JAN - JUNE | 2021

ISSN (E): 2663-1512, ISSN (P): 2617-3611

them to cultivate amicable relationships as well as friendships. They also confessed that they are not reluctant for cross-cultural marriages as they have established agreeable companies. They admitted that they have developed trust among the natives and are willing to coexist with them. Some of the participants claimed that they are influential as compared to the natives. Some of them mentioned that their younger generation is close to the local community, and one can hardly distinguish them from the local population. Their children have a good command over the native language, and no one can make any judgment to be distinct or of Afghan origin.

Social security and suitability are one of the essential aspects that drive them for the language shift. Through language, they want to be recognised among the local majority as they are in the minority. Being minor in the region makes them insecure and unsafe too. Hence, they learn the local language for affiliating themselves socially with the community they live in. Some of the participants reported that one could not assume himself safe by alienating oneself from society. They called group consciousness the protector of their rights and well-being.

Lastly, they wished to be called the natives as they have spent a considerable time of their lives here. They want to stay longer and to be recognised by the local culture. They exhibited great affection and affiliation with the region and considered the town their home and Punjabi their language. They said that they do not discriminate against any language based on any consideration. Although they speak their native language at their homes, they claim no harm to the local language.

\section{Discussion}

The business market is the domain mutually established by Pushto and Punjabi speakers in Punjab. The researchers observed that Pushto sellers and Punjabi buyers attempt to develop a common ground when they come across any business dealing. They believe it is mandatory to sustain the domain that addresses their lives as a whole. However, the domain is maintained through some linguistic features as the practitioners speak different languages. Both the parties usually converse in the common language, that is, Urdu.

In some cases, Pushto speakers use Punjabi terminology to develop rapport with the customers. They also practice this code-mixing to get their customers at ease because some customers are alien to the Urdu language or hesitant to speak in front of their family members 
UNIVERSITY OF CHITRAL JOURNAL OF LINGUISTICS AND LITERATURE

VOL. 5 | ISSUE I | JAN - JUNE | 2021

ISSN (E): 2663-1512, ISSN (P): 2617-3611

accompanying them. On the other hand, Punjabi speakers also attempt to use Pushto terminologies, especially when entering and asking for some concessions to fit the deal better. Through this common domain, they share knowledge, practices, and experiences.

Keeping in view the situation, they endeavour to create harmonious relationships with the local tenets to sustain their community which is the second significant pillar of CofP. The immigrants assume to be native speakers and staunch adherents to the region, which help them generate a soft corner in the hearts of the authorities. They also confessed that they have been producing a thriving business for the area and adopting the local culture. They coded that the genial affiliations they exhibit, the more they are safe. For the said reason, they have to promote regional language, which is instrumental for their businesses and regional safety.

Society is like a family for them and to which they have to adapt themselves. Some of the witty immigrants coded that these are we who have to adapt, not the society. They agreed upon the fact that people do not stay longer, but the community does. They reiterated the necessity of communal practices to share their experiences, knowledge, methods to adapt and develop their collaborative community. The participants wished not to be discriminated against based on their language and be considered prestigious as the locals. A few are privileged as they have never been discriminated against at any point in their daily life. They consider themselves prosperous in developing an amiable liaison with the local power groups. Some claim themselves as the dominant power in their localities.

\section{Conclusion}

Conclusively, language shift has become a universal phenomenon. It is not restricted to a specific region or a particular language family. It has become an inevitable linguistic phenomenon that is widespread in linguistic communities the world over. However, some triggering factors work as a force towards language shift. Some of the common factors are social, economic and political priorities.

Along with these factors, the displaced people also undergo the process of language shift. Last is the speakers' attitude, outlook, creed, and values, leading to the language shift. The research participants also suggested that businesses and livelihood always have greater prestige than language and culture. Consequently, no participant regretted this language shift as they 
UNIVERSITY OF CHITRAL JOURNAL OF LINGUISTICS AND LITERATURE

VOL. 5 | ISSUE I | JAN - JUNE | 2021

made no efforts to maintain their language. However, most participants reiterated the concept for two primary purposes: transactional, expanding their businesses, producing revenue; and, sustaining social interaction within the community they inhabit.

\section{Recommendations}

The study mainly highlighted the social and economic factors leading to the Afghan immigrants' intentional language shift. It took account of how the needs of financial stability and social cohesion play a pivotal role in thoughtful language shift. The study also explored the factors of political influence and power through the participants' responses. Yet, very few are explored and expressed on these factors. Therefore, it is further recommended that research studies solely address these two factors in discrete under the CofP model.

\section{References}

Ahmad, A. (2001, May 24). In Support of Punjabi Language. The Nation, Lahore, Opinion Page.

Ahmed, F. (1998). Ethnicity and Politics in Pakistan. New Delhi: Oxford University Press. Azam, I. (1980). Pakistan's National Culture and Character. Rawalpindi: Amir Publications.

Baart, L. G. and Sindhi, G. H. (2003). Pakistani languages and Society Problems and Prospects. Islamabad: National Institute of Pakistan Studies, Quaid-i-Azam University.

Chitkara, M.G. (1996). Mohajir’s Pakistan. New Delhi: APH Publishers.

Haarmann, H. (1986). Language in Ethnicity: a View of Basic Ecological Relations. New York: Walter de Gruyter.

Khan, A. (2005). Politics of Identity: Ethnic nationalism and the state in Pakistan. New Delhi: Sage Publications.

Mackey, W. F. (2006). The Ecology of Language Shift. In Alwin Fill and Peter Mühlhäusler (Eds.), The Ecolinguistics Reader: Language, Ecology and Environment (67-74). New York: Continuum International Publishing Group.

Moore, K.M. (2011). Pakistani Immigrants. Retrieved from https://www.religion.ucsb.edu/wp-content/uploads/4148-321-1pass-Pakistani.pdf

Rauf, A. (1975). Islamic Culture \& Civilisation in Pakistan. Lahore: Feroz Sons. 
Constitutive Features of Deliberate Language Shift: A Case Study of Afghan Immigrants as a Community of

UNIVERSITY OF CHITRAL JOURNAL OF LINGUISTICS AND LITERATURE

VOL. 5 | ISSUE I | JAN - JUNE | 2021

ISSN (E): 2663-1512, ISSN (P): 2617-3611

Raza, M. H. (1991). Cultural Caravan of Pakistan. Islamabad: Colorpix.

Rahman, Tariq. (2003). Language, Education and Culture. Karachi: Oxford University Press.

Salamat, Z. (1992). Pakistan 1947-58: A Historical Review. Islamabad: National Institute of Historical and Cultural Research.

Saleem, F. (2008, 8 June). Curriculum of Hate. The News, Islamabad, Opinion Page.

Shah, M. (1997). The Foreign Policy of Pakistan: Ethnic Impacts on Diplomacy, 1971- 1994. London: I.B.Tauris.

Wenger, E. (2004). Knowledge Management as a Doughnut. Retrieved from http://iveybusinessjournal.com/publication/knowledge-management-as-a-doughnut/

Wenger, E. (2010). Communities of Practice and Social Learning Systems: The Career of a Concept. In C. Blackmore (Ed.), Social Learning Systems and Communities of Practice (pp. 179-198). London: Springer. doi:10.1007/978-1-84996-133-2

Zaidi, A. (2010). A Postcolonial Sociolinguistics of Punjabi in Pakistan. Journal of Postcolonial Cultures and Societies, 1 (3), 22-55.

\begin{tabular}{|l|l|}
\hline (C) 2021 by the author. Licensee University of Chitral, Journal of Linguistics \& \\
Literature, Pakistan. This article is an open access article distributed under the \\
terms and conditions of the Creative Commons Attribution (CC BY) \\
(http://creativecommons.org/licenses/by/4.0/).
\end{tabular}

